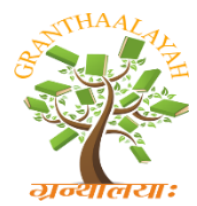

\author{
INTERNATIONAL JOURNAL OF RE
GRANTHAALAYAH \\ A knowledge Repository
}

Management

\title{
A SURVEY OF CONSUMERS' PURCHASE INTENTIONS IN ADVERTORIALS PROMOTION IN COMMUNITY BUSINESS
}

\author{
Li-Wei Lin ${ }^{* 1}$, Su-Rong Yan ${ }^{2}$, Jia-Lu Zhou ${ }^{3}$, Rajesh Kaluri ${ }^{4}$ \\ ${ }^{* 1,2,3}$ School of Information, Zhejiang University of Finance and Economics Dongfang College, \\ Zhejiang, China \\ ${ }^{4}$ Department of Software and Systems Engineering, VIT University, Vellore Tamil Nadu India
}

\begin{abstract}
Soft text promotion and planning has become one of the key factors in attracting consumers' purchase intentions. Soft text promotion includes the use of posters, videos, online live broadcasts and other related methods to achieve consumer purchase intentions. The most important part of community business is to establish a long-term partnership between buyers and sellers through these soft-text promotion methods. This paper is expected to issue 600 copies through questionnaires to see if consumers see the promotion of soft texts into purchase motives. Or the consumer in the purchase process, fancy a sense of identity with a certain brand. We have found that consumers are promoting their activities through soft papers, resulting in direct purchase intentions. The results show that consumers will look at the introduction of soft paper promotion and share information with other consumers. These factors will cause consumers to motivate to purchase intentions.
\end{abstract}

Keywords: Soft Text Promotion; Online Red Live Broadcast; Purchase Intention; Sharing Information.

Cite This Article: Li-Wei Lin, Su-Rong Yan, Jia-Lu Zhou, and Rajesh Kaluri. (2020). "A SURVEY OF CONSUMERS' PURCHASE INTENTIONS IN ADVERTORIALS PROMOTION IN COMMUNITY BUSINESS." International Journal of Research - Granthaalayah, 8(2), 100-107. https://doi.org/10.29121/granthaalayah.v8.i2.2020.190.

\section{Introduction}

Purchase intention has always been one of the important factors to observe consumers' motivation to purchase goods on social commerce platforms. Sellers always use different advertising methods to stimulate consumers. The concept of planned behavioral intention theory, TPB (Ajzen \& processes, 1991) is the most widely used model for explaining and analyzing human behavior. According to this theory, actions depend on the intention of the individual. It plays an increasingly important role in influencing consumers' willingness to buy, past studies conducted a metaanalysis and found strong empirical support for the use of intention to predict behavior (Sheppar, 
Hartwick, \& Warshaw, 1988). Social commerce is a huge platform, growing at an unprecedented rate around the world. When consumers shop in a social business environment, they will search the Internet for information and generate purchases (eMarketer, 2014; Google Consumer Barometer, 2015). According to this cognitive view, any information (for example, pictures, AD titles or metaphors) both can cause physical and experiential aspects of the purchase (Flavián, Gurrea, Orús, \& Informatics, 2017). If they can better understand which incentives enhance their intention to buy online, that will greatly help sellers who are running social commerce platforms.

In order to realize the advantages brought by increased purchase intention, it is of strategic significance to understand the factors influencing customer behavior in this field. Previous researchers have focused on modeling precursors to purchase intentions or independent variables of brand, trust, and information quality, See table 1.For example, researchers investigate trust in social presence and interaction with sellers (Lu, Fan, \&Zhou, 2016) ,familiar with platform, social presence, information search (Hajli, Sims, Zadeh, \&Richard, 2017). Some of the research is about the quality of information, the quality of websites, the impact on social commerce (Yusuf, Che Hussin, \&Busalim, 2018) There is little research on the emotional responses to the information projected by websites, such as metaphor, sensation, and taste. The former analogy is based on sellers' desire to deliver information to consumers in familiar and similar ways. The latter's sense and taste is based on his own experience reflecting the message to the receiver.

There is little research on the antecedents of social commercial purchase intentions, such as metaphors. Metaphors may suggest connections between them and memories of our experiences (Crilly, Moultrie, \&Clarkson, 2004) .Many researchers believe that so-called "metaphors" are cognitive operations of analogical reasoning that create new meanings (Richards 1936; Ortony 1979; MacCormac 1985; Haskell 1987) .Starting from the cognitive pathway, learning individuals' experience similarity reassembles a new cognitive system (Lakoff and Jonhson, 1980) .The relationship between metaphor and intelligibility emphasizes the importance of perception (Verbrugge\&McCarrell, 1977).

In this study, we use the perspective of experiential marketing to illustrate the role of metaphor. Schmitt (1999) introduced the concept of experiential marketing and proposed five ways to attract customers: feel, think, act and connect. The customer experience is holistic in nature. According to this view, the customer experience creation process can be understood as a value creation phase. When a person receives a metaphorical message, people interpret the message based on their own experience, familiarity, or something similar. If the recipient doesn't have a similar experience, they won't be able to understand the meaning of the metaphor. In order to make metaphor easier to understand, this study developed a research model to describe how metaphor can trigger consumers' emotional responses and affect their purchase intention.

In subsequent chapters, we begin with an overview of the metaphorical concepts used in social business. Next, we discuss the perception and taste factors that influence purchase intention, and propose new hypotheses and new research models. We then described the survey tools developed and the data collected from the latest social commerce platforms in Taiwan, and then tested the model using the structural equation model. Finally, we discuss the results, their practical implications and limitations, and recommendations for future research. 


\section{Literature review}

Experiential marketing focuses on the customer experience. According to research, customer experiences fall into two types. One is the accumulated knowledge between them, which is related to the past. The other is the perception, the feeling, the thought that comes from observation. It makes up the human sense. J. F. Schmitt \& Marketing, 2011) .Experience provides sensory, emotional, cognitive, behavioral, and relational values in place of functional values.

The customer experience is basically holistic. They are consumed as a series of comprehensive activities from before to after purchase. Before and after the actual transaction, the overall experience includes functional and emotional attributes and also creates internal and external value. Customer value is created by the overall experience of all elements (Grönroos, 2006 ). According to this view, the customer experience created can be understood as consisting of three value-creating phases: pre-use value, use-value, and post-use value. The focus of this study is on pre-use value, which refers to the customer's familiarity with the actual purchase, acquisition of knowledge, development of understanding, and try out the product or service as much as possible. This stage helps customers to shape their ideas and develop attitudes conducive to decision-making (Edvardsson, Enquist and Johnston, 2010). The concept of "pre-use value" is introduced to explain the booking service experience, thus providing vivid pictures. Real consumer experience. In other studies, videos were played in stores, and the information evoked sensory experiences (Brakus, Schmitt, \&Zarantonello, 2009). When consumers are stimulated, they will attract feelings through image, text and information triggering experience (b. j. j. o.m.m.schmitt, 1999).

In physical marketing, consumers can display products directly through display and trial. However, when experiencing a marketing shift to social commerce, most of the unique visual effects (such as images or text) remain. To better understand the factors that influence the importance of metaphor in this field, such as perception, taste, and purchase intention, we developed an empirical research model whose constructs and assumptions are discussed in the next section.

\section{Theoretical Framework and Hypothesis Development}

Figure 1 shows the relationships between the components of the entire research model. We graphically present the influence of image-led metaphor and perception on the interaction of taste, the influence of text-led advertorial promotion and perception on taste, and the influence of the interaction between taste and sense on purchase intention. Three hypotheses were tested against the model. Each hypothesis is represented by the letter $\mathrm{H}$ and a number. The arrows represent hypothetical relationships. 


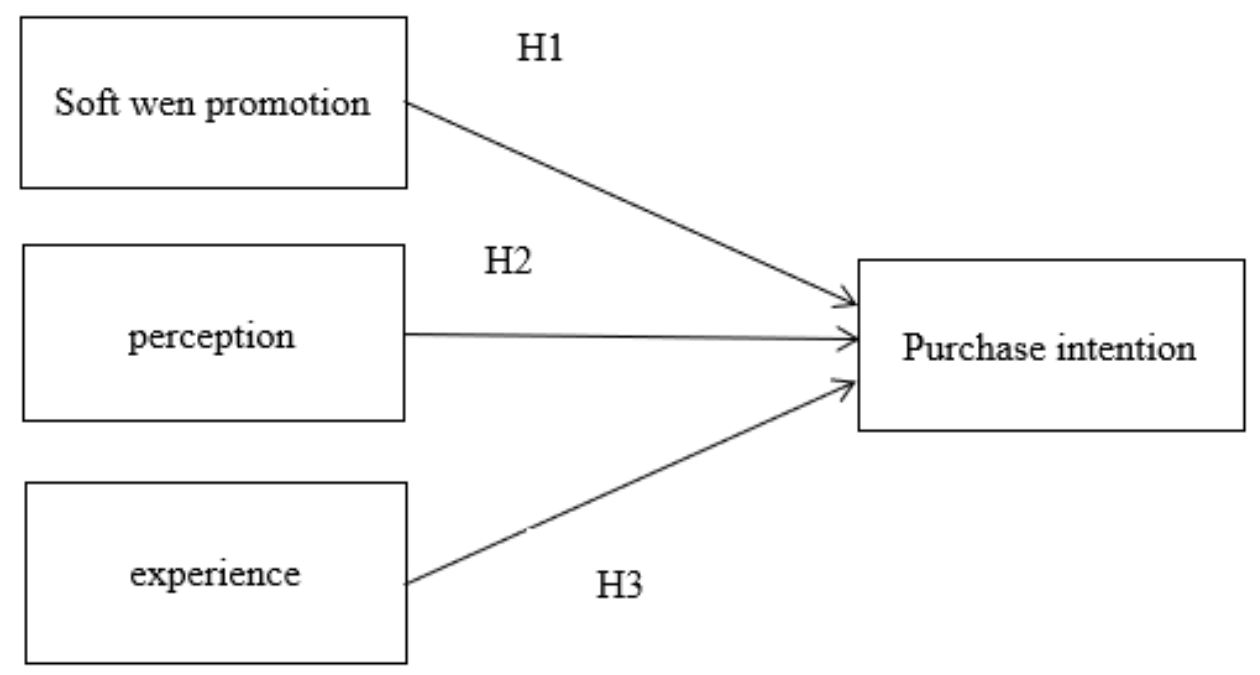

Figure 1: studies the architecture diagram

The purpose of sensory attraction is to create sensory experience through sight, sound, touch, taste and smell (B. J. J. o.m.m.Schmitt, 1999). In experiential marketing, the first interaction between the consumer and the brand occurs through a strong exposure to the sensory stimuli of the brand. According to Brakus et al.(2009), signs, mascot, logo and design (name, logo, color), brand packaging, brand communication (advertising, brochures, website) and brand environment (shops, activities), consumers must entice him all the levels of the five senses with a strong emotional connection consumers and brand the way form (BJJomm Schmitt, 1999). The more sensory memories activated, the stronger the connection between the brand and consumers (Lindstrom \& Management, 2005). Metaphors work by mapping knowledge structures so that humans can interpret and understand them based on prior knowledge and novel or unfamiliar experiences (Lakoff\&Johnson, 1999). Metaphors can be explained through cognitive, emotional, and experiential processes. When consumers accept the semantics of metaphorical advertising, they need to mobilize their cognitive resources and evoke more empirical explanations (Chang, $\mathrm{Wu}$, Lee, \&Chu, 2018). If the recipient of the message does not have the relevant experience and knowledge, he will not be able to receive the meaning of the message he really wants to convey. Taste is defined as a state of mindfulness in which consumers appreciate the pleasure they experience in the moment of result or experience. Happiness is a wide range of concepts, including sensory enjoyment from physical sensations, aesthetic pleasure from natural or man-made phenomena, and the joy of realizing the ideal (Bryant \& Veroff, 2007). In fact, people can experience happiness from various places, such as eating food, reading novels or enjoying beautiful things. Researchers have studied how continuous experiences (e.g., cake tasting and distraction eating) increase the enjoyment of the experience (Dube\&Bel, 2001). Some marketers will encourage consumers to participate in different consumption activities before consumption, and induce the aftertaste of consumers to make the waiting time more pleasant and improve the enjoyment of the actual experience (Chun, Diehl, \&MacInnis, 2017).Another study shows that adding a strong hedonic dimension to the actual product (for example, the color of the iMac computer) not only enhances the functional utility of the product, but also enhances consumers' taste and expectations, making them willing to buy or prepay (Patrick \&Park, 2006).

Therefore, it is assumed that: 
H1: the influence of advertorials promotion on consumers' buying intentions is positively correlated

$\mathrm{H} 2$ : perception increases the positive correlation of consumers' purchase intention

H3: experience increases the positive correlation of consumers' purchase intentions

\section{Research method}

To develop survey tools, a set of items was identified from the literature to measure the construction of the research model. Data from the survey samples are used to assess the validity and reliability of the instrument and to test the relationship between hypotheses.

\subsection{Content Validity}

All the measures in the survey tools are proposed from the literature. Where appropriate, the way the project is presented is adjusted to the context of the social business. English is first developed, then translated into Chinese, then translated into English. When the translated English version is checked against the original English version, some questions are rewritten to improve the accuracy of the translation. Where appropriate, the project expression was adjusted to fit the context of the social business industry. The items were measured on a 7-point likert scale, ranging from "strongly disagree" (1) to "strongly agree" (7).

\subsection{Preliminary Text and Pilot Tests}

To improve the content and appearance of the questionnaire, a predictive test was conducted on a sample of five academic researchers and four PHDS. Students asked respondents to fill out questionnaires and comment on the wording, understanding and clarity of the items as well as the overall appearance and content of the document. In response to the proposal, all statements were retained, subject to only a second amendment. Two other academic researchers were further examined after the instrument was thought to be ready to be sent to a large sample to collect data to test our study model.

\subsection{Data Collection}

The empirical study targeted Internet users who had experience with online shopping customers. Choosing online surveys for fast and accurate data collection is easier to complete than traditional paper surveys. To maximize the response, all respondents who responded effectively were randomly selected, and 50 respondents were rewarded. Finally, we expect to collect 1067 questionnaires as the minimum sample size in this study.

\section{Conclusion and Discussion}

This study mainly discusses the influence of advertorials promotion, increased perception and experience on consumers' purchase intention. The biggest contribution of this study is to fill in the research of advertorials promoting consumers' purchase intentions. In recent years, few scholars have studied the purchase intention of advertorials. The biggest limitation of this study is that it only focuses on the Taiwan market. This is a new concept and a new business model. If consumers 
can be included in different countries in the future, the direction of the survey will be different. Here are some of my Suggestions for future researchers that I hope will help them:

1) The objects of the questionnaire are:

The main questionnaire released in this study is targeted at the Taiwan market and suggests that future researchers can expand abroad. This kind of research will help to improve the value of the whole e-commerce consumer purchase intention data survey.

2) Research objects can distinguish their different variables:

Our research focuses on the purchase intentions of some Chinese and Taiwanese e-commerce platforms. It is suggested that future researchers could investigate the status of their medical surveillance systems among consumer groups in different countries. The subdivision of variables will lead to differences in their results. This was also suggested by later researchers, who could look at different variables from these dimensions.

\section{Acknowledgement}

This research was supported by the NSF Grant Nos.61972337 and 61502414.

\section{References}

[1] Ajzen, I. J. O. b., \& processes, h. d. (1991). The theory of planned behavior. 50(2), 179-211.

[2] Black M (1979) More about metaphor. In: Ortony A(ed.) Metaphor and Thought, pp.19-43. Cambridge, UK: Cambridge University Press.

[3] Black, M. (1962). Models and metaphors: Studies in language and philosophy.

[4] Brakus, J. J., Schmitt, B. H., \& Zarantonello, L. J. J. o. m. (2009). Brand experience: what is it? How is it measured? Does it affect loyalty? , 73(3), 52-68.

[5] Bryant, F. B., \& Veroff, J. (2007). Savoring: A New Model of Positive Experience: Lawrence Erlbaum Associates, Publishers.

[6] Centner, D., and Jeziorski, M. (1993). The shift from metaphor to analogy in western science. In A. Ortony, Ed., Metaphor and thought (2d ed.), pp. 447-480. Cambridge: Cambridge University Press.

[7] Centner, D. (1982). Are scientific analogies metaphors? In D. Miall, Ed., Metaphor: Problems and perspectives, pp. 106-132. Brighton: Harvester.

[8] Chang, C.-T., Wu, Y.-C., Lee, Y.-K., \& Chu, X.-Y. J. I. J. o. A. (2018). Right metaphor, right place: choosing a visual metaphor based on product type and consumer differences. 37(2), 309-336.

[9] Chun, H. H., Diehl, K., \& MacInnis, D. J. J. J. o. M. (2017). Savoring an upcoming experience affects ongoing and remembered consumption enjoyment. 81(3), 96-110.

[10] Crilly, N., Moultrie, J., \& Clarkson, P. J. J. D. s. (2004). Seeing things: consumer response to the visual domain in product design. 25(6), 547-577.

[11] Dube, L., \& Bel, J. L. L. J. A. E. A. (2001). A differentiated view of pleasure: Review of the literature and research propositions.

[12] Edvardsson, B., Enquist, B., \& Johnston, R. J. M. S. Q. A. I. J. (2010). Design dimensions of experience rooms for service test drives: case studies in several service contexts. 20(4), 312-327.

[13] Fainsilber, L., Ortony, A. J. M., \& Symbol. (1987). Metaphorical uses of language in the expression of emotions. 2(4), 239-250.

[14] Flavián, C., Gurrea, R., Orús, C. J. T., \& Informatics. (2017). The influence of online product presentation videos on persuasion and purchase channel preference: The role of imagery fluency and need for touch. 34(8), 1544-1556.

[15] Gibbs, R. W, Jr. (1994). The poetics of mind: Figurative thought, language, and understanding. New York: Cambridge University Press. 
[16] Gruber, H. E. (1995). Insight and affect in the history of science. In R. J. Stern-berg and J. E. Davidson, Eds., The nature of insight, pp. 397-432. Cambridge, MA: MIT Press.

[17] Grönroos, C. J. M. t. (2006). Adopting a service logic for marketing. 6(3), 317-333.

[18] Haskell, Robert E. (1987), Cognition and Symbolic Structures: The Psychology of Metaphoric Transformation, Norwood, NJ: Ablex Publishing.

[19] Hajli, N., Sims, J., Zadeh, A. H., \& Richard, M.-O. J. J. o. B. R. (2017). A social commerce investigation of the role of trust in a social networking site on purchase intentions. 71, 133-141.

[20] Hobbs, J. R. (1979). Metaphor, metaphor schemata, and selective inferencing. Technical Note 204, SRI Projects 7910 and 7500. Menlo Park, CA: SRI International.

[21] Lakoff, G., and Johnson, M. (1980). Metaphors we live by. Chicago: University of Chicago Press.

[22] Lakoff, G., \& Johnson, M. (1999). Philosophy in the Flesh (Vol. 4): New york: Basic books.

[23] Lakoff, G., and Turner, M. (1989). More than cool reason: A field guide to poetic metaphor. Chicago: University of Chicago Press.

[24] Li, Q., Liang, N., \& Li, E. Y. J. E. C. R. (2018). Does friendship quality matter in social commerce? An experimental study of its effect on purchase intention. 18(4), 693-717.

[25] Lin, Z., Yang, Z. J. F. L. T., \& Research. (2010). A study of semantic relations and rankshift directions in grammatical metaphor [J]. 6, 403-410.

[26] Lindstrom, M. J. J. o. P., \& Management, B. (2005). Broad sensory branding. 14(2), 84-87.

[27] Lu, B., Fan, W., \& Zhou, M. J. C. i. H. B. (2016). Social presence, trust, and social commerce purchase intention: An empirical research. 56, 225-237.

[28] MacCormac, Earl R. (1985), A Cognitive Theory of Metaphor, Cambridge, MA: Bradford Books, MIT Press.

[29] Mccracken, J. C., \& Macklin, M. C. J. M. L. (1998). The role of brand names and visual cues in enhancing memory for consumer packaged goods. 9(2), 209-226.

[30] Meeds, R., Liginlal, D., Ahmad, R., \& Gopinath, P. (2016). THE EFFECTS OF CULTURAL DESIGN STYLE AND INFORMATION RICHNESS ON CONSUMERS'VISUAL ATTENTION, COMPREHENSION AND ATTITUDES TOWARD ARABIC-LANGUAGE WEBSITES. Paper presented at the American Academy of Advertising. Conference. Proceedings (Online).

[31] Miller, G. A. (1993). Images and models, similes and metaphors. In A. Ortony, Ed., Metaphor and thought (2d ed.), pp. 357-400. Cambridge: Cambridge University Press.

[32] Miller, J. H. J. A. B. (1979). The Function of Rhetorical Study at the Present Time. 62, 10-18.

[33] Morgan, S. E., \& Reichert, T. J. J. o. A. (1999). The message is in the metaphor: Assessing the comprehension of metaphors in advertisements. 28(4), 1-12.

[34] Nersessian, N. J. (1992). How do scientists think? Capturing the dynamics of conceptual change in science. In R. N. Giere and H. Feigl, Eds., Cognitive models of science: Minnesota studies in the philosophy of science, pp. 3-44. Minneapolis: University of Minnesota Press.

[35] Ortony, Andrew (1979), "Beyond Literal Similarity," Psychological Review, 86, 161-180.

[36] Ortony, A., \& Fainsilber, L. (1987). The role of metaphors in descriptions of emotions. Paper presented at the Proceedings of the 1987 workshop on Theoretical issues in natural language processing.

[37] Patrick, V. M., \& Park, C. W. J. J. o. R. (2006). Paying before consuming: Examining the robustness of consumers' preference for prepayment. 82(3), 165-175.

[38] Schmitt, B. J. F., \& Marketing, T. i. (2011). Experience marketing: concepts, frameworks and consumer insights. 5(2), 55-112.

[39] Schmitt, B. J. J. o. m. m. (1999). Experiential marketing. 15(1-3), 53-67.

[40] Sheppard, B. H., Hartwick, J., \& Warshaw, P. R. J. J. o. c. r. (1988). The theory of reasoned action: A meta-analysis of past research with recommendations for modifications and future research. 15(3), 325-343. 
DOI: 10.5281/zenodo.3692611

[41] Stainbrook, E. J. (2003). Reading comics: A theoretical analysis of textuality and discourse in the comics medium, doctoral dissertation. IndianaCounty: Indiana University of Pennsylvania.

[42] Steen, G. J. (1989). Metaphor and literary comprehension: Towards a discourse theory of metaphor in literature. Poetics, 18:113-141.

[43] Sundar, A., \& Noseworthy, T. J. J. J. o. M. (2014). Place the logo high or low? Using conceptual metaphors of power in packaging design. 78(5), 138-151.

[44] Tasić, M., Stamenković, D. J. P.-S., \& Sciences, B. (2015). The interplay of words and images in expressing multimodal metaphors in comics. 212, 117-122.

[45] Verbrugge, R. R., \& McCarrell, N. S. J. C. p. (1977). Metaphoric comprehension: Studies in reminding and resembling. 9(4), 494-533.

[46] Yusuf, A. S., Che Hussin, A. R., \& Busalim, A. H. J. J. o. S. M. (2018). Influence of e-WOM engagement on consumer purchase intention in social commerce

*Corresponding author.

E-mail address: linlw1982@gmail.com 